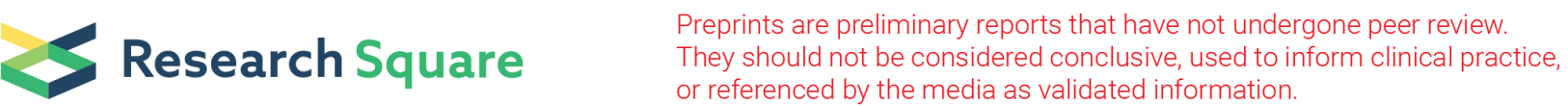

\section{Transcatheter Aortic Valve Implantation Versus Surgical Aortic Valve Replacement in Low-Risk Patients: A Meta-Analysis Based On a 2-Year Follow-Up}

\section{Chang-Gan Chen}

Fujian Medical University Union Hospital

\section{Bei-Bei Xi}

Fujian Medical University Union Hospital

\section{Qiu-Feng Deng}

Fujian Medical University Union Hospital

\section{Xin-Yuan Zhang}

Fujian Medical University Union Hospital

\section{Wei-Cheng Lin}

Fujian Medical University Union Hospital

\section{Liang-Wan Chen}

Fujian Medical University Union Hospital

\section{Zhi-Huang Qiu ( $\nabla$ qzhflm@126.com )}

Fujian Medical University Union Hospital https://orcid.org/0000-0002-5917-8968

Research article

Keywords: TAVI, SAVR, aortic stenosis, meta-analysis, low risk

Posted Date: September 17th, 2021

DOI: https://doi.org/10.21203/rs.3.rs-855993/v1

License: (c) (i) This work is licensed under a Creative Commons Attribution 4.0 International License. Read Full License 


\section{Abstract}

Background: Previous studies have shown that transcatheter aortic valve implantation (TAVI) is the best alternative therapy to surgical aortic valve replacement (SAVR) in high-risk surgical patients with aortic stenosis (AS). However, it is not clear whether TAVI can be utilised in low-risk surgical patients with AS. This study aimed to evaluate the safety and efficacy of TAVI in low-risk patients.

Methods: From the outset of our initiative until June 2021, PubMed, EMBASE, and Cochrane were thoroughly searched, yielding the selection of 3 randomised controlled trials including 2633 patients with AS, to assess outcome measures at distinct follow-up time periods.

Results: The mean Society of Thoracic Surgeons Predicted Risk of Mortality score of patients was 2.2. At the 30-day and 1-year follow-up, TAVI was associated with a lower incidence of all-cause mortality, cardiovascular mortality, acute kidney injury (stage 2 or 3), life-threatening or significant bleeding, and new atrial fibrillation (NAF), but an increased risk of permanent pacemaker implantation. At the 2-year follow-up, TAVI only had an advantage in NAF (RR, 0.27; $95 \% \mathrm{Cl}, 0.14-0.51 ; \mathrm{P} 0.0001)$ without any significant difference in any of the other outcome measures.

Conclusions: For low-risk surgical patients with AS, the efficacy of TAVI was superior to that of SAVR by the 30-day and 1-year follow-up. This was most evident by the 2-year follow-up, except for the advantages of NAF, with no other significant differences.

\section{Introduction}

Aortic stenosis (AS) is a common heart valve disorder in the elderly with increasing incidence in the ageing population. ${ }^{[1]}$ Currently, there is no effective therapy for this condition, as valve replacement is the standard of care. Historically, surgical aortic valve replacement (SAVR) is regarded as the gold standard for patients with severe AS. ${ }^{[2]}$ As a novel modality, transcatheter aortic valve implantation (TAVI) has garnered significant support for its use over the years since its first application in $2002^{[3]}$, and it is currently the best alternative to SAVR in high-risk surgical patients with AS. ${ }^{[4]}$

The PARTNER trial shows that the efficacy of TAVI is non-inferior to that of SAVR ${ }^{[5]}$ in intermediate-risk patients with AS, prompting the American College of Cardiology to recommend TAVI for intermediate-risk patients (class lla). ${ }^{[6]}$ However, complications due to TAVI, such as paravalvular leakage and durability, are still a cause for concern. ${ }^{[7]}$ Industry experts are in discussion on whether TAVI can be widely used in low-risk surgical patients with AS. Several randomised controlled trials (RCTs) have been conducted on this matter ${ }^{[8,9]}$, but the results from these experiments and meta-analyses are not consistent. The latest 2020 guidelines still list SAVR only as a class I treatment for low-risk surgical patients without recommending TAVI in this patient subset. ${ }^{[10]}$ The two-year follow-up results published in the PARTNER III study ${ }^{[11]}$ (by Martin et al.) did provide some evidence to suggest that further investigation of the efficacy of TAVI versus that of SAVR in low-risk surgical patients with AS would be prudent. As a result, we 
conducted a new meta-analysis to compare TAVI with SAVR to clearly delineate their performance based on different time frames and patient risk stratification.

\section{Materials And Methods}

\section{Eligibility criteria}

The research program follows the PRIMA-P guidelines ${ }^{[12]}$, and this article is based on the Preferred Reporting Items for Systematic Reviews and Meta-Analyses guidelines. ${ }^{[13]}$ The inclusion criteria were as follows: (1) Population: low-risk surgical patients (Society of Thoracic Surgeons Predicted Risk of Mortality, STS PROM 4\%); (2) Comparison: TAVI; (3) Control: SAVR; (4) Outcomes: Primary outcomes were all-cause mortality and secondary outcomes were cardiovascular mortality, stroke, transient ischaemic attack (TIA), myocardial infarction (MI), acute kidney injury (stage 2 or 3 ), life-threatening or significant bleeding, permanent pacemaker implantation (PPI), and new atrial fibrillation (NAF); these outcome measures were assessed over a 2-year period. ${ }^{[14]}$; (5) Study design: RCTs.

\section{Literature search}

From the outset to June 13, 2021, we conducted a comprehensive, systematic search of PubMed, EMBASE, and Cochrane. ClinicalTrials.gov trial registries were also reviewed to determine if the available results were reported from ongoing or completed studies. Our supplement details the study strategy.

\section{Data analyses}

Two authors separately collected the required, relevant data with any discrepancies between them being resolved by group consultation. The two authors used the Cochrane collaborative bias risk tool to assess the risk of bias independently in five aspects and used the Grading of Recommendations, Assessment, Development and Evaluation (GRADE) to estimate the quality of evidence for each outcome. ${ }^{[15]}$ The results of each RCT were assigned as dichotomous data, analysed by the Mantel Haenszel method, and presented as relative risk (RR). The summary RR and $95 \%$ confidence interval (Cl) of the survey results were calculated using a random effect model. ${ }^{[16]} \mathrm{P} \leq 0.5$ was considered to be statistically significant, and heterogeneity was assessed through $I$-square $\left(I^{2}\right)$ and $Q$ statistics; $I^{2}>50 \%$ is considered substantial[ ${ }^{[17,18]}$. Using funnel plots ${ }^{[19]}$, Egger and Begg tests were conducted to evaluate the publication bias of studies with reported results $\geq 10$. ${ }^{[20]}$

\section{Results}

Figure 1 details the study selection process, illustrating a total of 2389 retrieved articles with 963 duplicates, deleted by the Endnote X9 software. After reviewing the titles and abstracts, 1394 repetitive literature reviews, case reports, meta-analyses, and unrelated articles were excluded. Twenty-nine items were further excluded based on the inclusion criteria, resulting in the final 3 articles. Table 1 comprises 
the details of the included studies, as 2633 patients with AS across the 3 cohorts were enrolled (EVOLUT ${ }^{[8]}$, NOTION ${ }^{[9,14]}$, and PARTNER III $^{[11]}$ ). In the assessment of deviation risk, due to specific study designs, it is impossible to blind operators or patients (Supplement Figs A. and B.). Summary of findings and strength of evidence (GRADE) are shown in Supplement ( Table B. C. and D.), the quality of evidence for the most results is evaluated as high. Because fewer than 10 studies were included, we did not perform tests to assess publication bias. 
Table 1

Characteristics of studies and patients

\begin{tabular}{|c|c|c|c|c|}
\hline \multicolumn{2}{|l|}{ Study } & NOTION & $\begin{array}{l}\text { PARTNER } \\
\text { III }\end{array}$ & EVOLUT \\
\hline \multicolumn{2}{|l|}{ Number of centers } & 3 & 71 & 86 \\
\hline \multicolumn{2}{|l|}{$\begin{array}{l}\text { Recruitment } \\
\text { period }\end{array}$} & $2011-2013$ & $\begin{array}{l}2012- \\
2016\end{array}$ & $\begin{array}{l}2016- \\
2018\end{array}$ \\
\hline \multicolumn{2}{|l|}{ Valve Type } & $\begin{array}{l}\text { CoreValve, Evolut R, or Evolut } \\
\text { PRO }\end{array}$ & Sapien 3 & CoreValve \\
\hline \multirow[t]{2}{*}{ sample size } & TAVI & 145 & 496 & 725 \\
\hline & SAVR & 135 & 454 & 678 \\
\hline \multirow[t]{2}{*}{ male -no. (\%) } & TAVI & $78(53.8)$ & $335(67.5)$ & $464(64.0)$ \\
\hline & SAVR & $71(52.6)$ & $323(71.1)$ & $449(66.2)$ \\
\hline \multirow[t]{2}{*}{ Mean year } & TAVI & $79.2 \pm 4.9$ & $73.3 \pm 5.8$ & $74.1 \pm 5.8$ \\
\hline & SAVR & $79 \pm 4.7$ & $73.6 \pm 6.1$ & $73.6 \pm 5.9$ \\
\hline \multirow[t]{2}{*}{ Mean STS-PROM score } & TAVI & $2.9 \pm 1.6$ & $1.9 \pm 0.7$ & $1.9 \pm 0.7$ \\
\hline & SAVR & $3.1 \pm 1.7$ & $1.9 \pm 0.6$ & $1.9 \pm 0.7$ \\
\hline \multirow{2}{*}{$\begin{array}{l}\text { Prior cerebrovascular accident - } \\
\text { no. }(\%)\end{array}$} & TAVI & $24(16.6)$ & $17(3.4)$ & $74(10.2)$ \\
\hline & SAVR & $22(16.3)$ & $23(5.1)$ & $80(11.8)$ \\
\hline \multirow{2}{*}{$\begin{array}{l}\text { Prior myocardial infarction -no. } \\
(\%)\end{array}$} & TAVI & $8(5.5)$ & $28(5.7)$ & $48(6.6)$ \\
\hline & SAVR & $6(4.4)$ & $26(5.8)$ & $33(4.9)$ \\
\hline \multirow{2}{*}{$\begin{array}{l}\text { Peripheral vascular disease -no. } \\
(\%)\end{array}$} & TAVI & $6(4.1)$ & $34(6.9)$ & $54(7.5)$ \\
\hline & SAVR & $9(6.7)$ & $33(7.3)$ & $56(8.3)$ \\
\hline \multirow{2}{*}{$\begin{array}{l}\text { Chronic lung disease } \\
\text {-no. (\%) }\end{array}$} & TAVI & $17(11.7)$ & $25(5.1)$ & $\begin{array}{l}104 \\
(15.0)\end{array}$ \\
\hline & SAVR & $16(11.9)$ & $28(6.2)$ & $\begin{array}{l}117 \\
(18.0)\end{array}$ \\
\hline \multirow{2}{*}{$\begin{array}{l}\text { Diabetes mellitus } \\
\text {-no. (\%) }\end{array}$} & TAVI & $26(17.9)$ & $\begin{array}{l}155 \\
(31.2)\end{array}$ & $\begin{array}{l}228 \\
(31.4)\end{array}$ \\
\hline & SAVR & $28(20.7)$ & $\begin{array}{l}137 \\
(30.2)\end{array}$ & $\begin{array}{l}207 \\
(30.5)\end{array}$ \\
\hline \multirow{2}{*}{$\begin{array}{l}\text { Creatinine level } \\
>2 \text { mg/dl -no. (\%) }\end{array}$} & TAVI & $2(1.4)$ & $1(0.2)$ & $3(0.4)$ \\
\hline & SAVR & $1(0.7)$ & $1(0.2)$ & $1(0.1)$ \\
\hline
\end{tabular}


TAVl: transcatheter aortic valve implantation

SAVR: surgical aortic valve replacement

Table 2 displays the results of all outcome analyses. The EVOLUT trial has yet to complete a two-year follow-up of all participants, so we did not include the trial in our analysis of the 2-year results to avoid bias in the analysis. The results of the 30-day, 1-year, and 2-year follow-ups are shown in Fig. 2, Fig. 3, and Fig. 4 respectively. At the 30-day follow-up of the low-risk surgical patients with AS, TAVI was associated with a lower incidence of all-cause mortality (RR, $0.44 ; 95 \% \mathrm{Cl}, 0.20$ to $0.98 ; \mathrm{P}=0.04)$, acute kidney injury (stage 2 or 3 ) (RR, $0.27 ; 95 \% \mathrm{Cl}, 0.14$ to 0.56 ; $\mathrm{P}=0.0003)$, life-threatening or significant bleeding (RR, $0.29 ; 95 \% \mathrm{Cl}, 0.14$ to $0.61 ; \mathrm{P}=0.001)$, and NAF (RR, $0.21 ; 95 \% \mathrm{Cl}, 0.14$ to $0.31 ; \mathrm{P}<0.00001)$, but an increased risk of PPI (RR, 3.59; $95 \% \mathrm{Cl}, 1.43$ to $9.03 ; \mathrm{P}=0.006)$. 
Table 2

Subgroup analyses at the 30-day, 1-year and 2-year follow-up.

\begin{tabular}{|c|c|c|c|c|c|c|}
\hline \multirow{2}{*}{$\begin{array}{l}\text { Research end point } \\
\text { Low-risk group }\end{array}$} & \multirow[t]{2}{*}{$\begin{array}{l}\text { Research } \\
\text { number }\end{array}$} & \multicolumn{2}{|c|}{$\begin{array}{l}\text { Heterogeneity } \\
\text { test }\end{array}$} & \multicolumn{2}{|c|}{ Outcome } & \multirow[b]{2}{*}{$P$ value } \\
\hline & & $P$ value & $\mathrm{I}^{2}(\%)$ & $\mathrm{RR}$ & $95 \% \mathrm{Cl}$ & \\
\hline \multicolumn{7}{|l|}{ 30-days } \\
\hline All-cause mortality & 3 & 0.92 & $\mathrm{I}^{2}=0$ & 0.44 & $\begin{array}{l}{[0.20} \\
0.98]\end{array}$ & 0.04 \\
\hline Cardiovascular mortality & 3 & 0.95 & $\mathrm{I}^{2}=0$ & 0.47 & $\begin{array}{l}{[0.21} \\
1.03]\end{array}$ & 0.06 \\
\hline Stroke & 3 & 0.11 & $\begin{array}{l}1^{2}= \\
54\end{array}$ & 0.57 & $\begin{array}{l}{[0.22} \\
1.48]\end{array}$ & 0.25 \\
\hline Transient ischemic attack & 3 & 0.25 & $\begin{array}{l}1^{2}= \\
27\end{array}$ & 0.75 & $\begin{array}{l}{[0.17} \\
3.37]\end{array}$ & 0.71 \\
\hline Myocardial infarction & 3 & 0.81 & $I^{2}=0$ & 0.65 & $\begin{array}{l}{[0.34} \\
1.22]\end{array}$ & 0.18 \\
\hline $\begin{array}{l}\text { Acute kidney injury } \\
\text { ( stage } 2 \text { or } 3 \text { ) }\end{array}$ & 3 & 0.54 & $\mathrm{I}^{2}=0$ & 0.27 & $\begin{array}{l}{[0.14} \\
0.56]\end{array}$ & 0.0003 \\
\hline $\begin{array}{l}\text { Life-threatening or disabling } \\
\text { bleeding }\end{array}$ & 3 & 0.002 & $\begin{array}{l}1^{2}= \\
83\end{array}$ & 0.29 & $\begin{array}{l}{[0.14} \\
0.61]\end{array}$ & 0.001 \\
\hline $\begin{array}{l}\text { Permanent pacemaker } \\
\text { implantation }\end{array}$ & 3 & 0.002 & $\begin{array}{l}1^{2}= \\
84\end{array}$ & 3.59 & $\begin{array}{l}{[1.43} \\
9.03]\end{array}$ & 0.006 \\
\hline New-atrial fibrillation & 3 & 0.03 & $\begin{array}{l}1^{2}= \\
72\end{array}$ & 0.21 & $\begin{array}{l}{[0.14} \\
0.31]\end{array}$ & $<0.00001$ \\
\hline \multicolumn{7}{|l|}{ 1-year } \\
\hline All-cause mortality & 3 & 0.52 & $I^{2}=0$ & 0.69 & $\begin{array}{l}{[0.43,} \\
1.10]\end{array}$ & 0.12 \\
\hline Cardiovascular mortality & 3 & 0.83 & $\mathrm{I}^{2}=0$ & 0.56 & $\begin{array}{l}{[0.33} \\
0.94]\end{array}$ & 0.03 \\
\hline Stroke & 3 & 0.24 & $I^{2}=0$ & 0.71 & $\begin{array}{l}{[0.40} \\
1.25]\end{array}$ & 0.23 \\
\hline Transient ischemic attack & 3 & 0.91 & $I^{2}=0$ & 0.98 & $\begin{array}{l}{[0.52,} \\
1.83]\end{array}$ & 0.94 \\
\hline Myocardial infarction & 3 & 0.57 & $1^{2}=0$ & 0.74 & $\begin{array}{l}{[0.43,} \\
1.27]\end{array}$ & 0.28 \\
\hline
\end{tabular}




\begin{tabular}{|c|c|c|c|c|c|c|}
\hline \multirow{2}{*}{$\begin{array}{l}\text { Research end point } \\
\text { Life-threatening or disabling } \\
\text { bleeding }\end{array}$} & \multirow{2}{*}{$\begin{array}{l}\text { Research } \\
\text { number }\end{array}$} & \multicolumn{2}{|c|}{$\begin{array}{l}\text { Heterogeneity } \\
\text { test }\end{array}$} & \multicolumn{2}{|c|}{ Outcome } & \multirow[b]{2}{*}{$<0.00001$} \\
\hline & & 0.53 & $\mathrm{I}^{2}=0$ & 0.32 & $\begin{array}{l}{[0.24,} \\
0.42]\end{array}$ & \\
\hline $\begin{array}{l}\text { Permanent pacemaker } \\
\text { implantation }\end{array}$ & 3 & 0.0002 & $\begin{array}{l}1^{2}= \\
88\end{array}$ & 3.42 & $\begin{array}{l}{[1.33,} \\
8.82]\end{array}$ & 0.01 \\
\hline New-atrial fibrillation & 3 & 0.03 & $\begin{array}{l}1^{2}= \\
69\end{array}$ & 0.25 & $\begin{array}{l}{[0.18,} \\
0.36]\end{array}$ & $<0.00001$ \\
\hline \multicolumn{7}{|l|}{ 2-years } \\
\hline All-cause mortality & 2 & 0.99 & $1^{2}=0$ & 0.79 & $\begin{array}{l}{[0.46} \\
1.35]\end{array}$ & 0.38 \\
\hline Cardiovascular mortality & 2 & 0.83 & $\mathrm{I}^{2}=0$ & 0.66 & $\begin{array}{l}{[0.36,} \\
1.20]\end{array}$ & 0.17 \\
\hline Stroke & 2 & 0.96 & $\mathrm{I}^{2}=0$ & 0.68 & $\begin{array}{l}{[0.37} \\
1.26]\end{array}$ & 0.22 \\
\hline Transient ischemic attack & 2 & 0.21 & $\begin{array}{l}1^{2}= \\
36\end{array}$ & 1.09 & $\begin{array}{l}{[0.39} \\
3.04]\end{array}$ & 0.87 \\
\hline Myocardial infarction & 2 & 0.99 & $\mathrm{I}^{2}=0$ & 0.79 & $\begin{array}{l}\text { [0.46, } \\
1.35]\end{array}$ & 0.38 \\
\hline $\begin{array}{l}\text { Permanent pacemaker } \\
\text { implantation }\end{array}$ & 2 & $<0.0001$ & $\begin{array}{l}1^{2}= \\
94\end{array}$ & 3.58 & $\begin{array}{l}{[0.45} \\
28.74]\end{array}$ & 0.23 \\
\hline New-atrial fibrillation & 2 & 0.009 & $\begin{array}{l}1^{2}= \\
85\end{array}$ & 0.27 & $\begin{array}{l}{[0.14} \\
0.51]\end{array}$ & $<0.0001$ \\
\hline
\end{tabular}

At the 1-year follow-up of the low-risk surgical patients with AS, the cardiovascular mortality (RR, 0.56; $95 \% \mathrm{Cl}, 0.33$ to $0.94 ; \mathrm{P}=0.03)$, life-threatening or significant bleeding (RR, $0.32 ; 95 \% \mathrm{Cl}, 0.24$ to 0.42 ; $\mathrm{P}<0.00001)$ and the NAF (RR, $0.25 ; 95 \% \mathrm{Cl}, 0.18$ to $0.36 ; \mathrm{P}<0.00001)$ results in the TAVI group were superior to those in the SAVR group, but TAVI group was inferior to the SAVR group for the incidence of $\mathrm{PPI}(\mathrm{RR}, 3.42 ; 95 \% \mathrm{Cl}, 1.33$ to $8.82 ; \mathrm{P}=0.01)$.

At the 2-year follow-up of low-risk surgical patients with AS, only the NAF results ( $R R, 0.27 ; 95 \% \mathrm{Cl}, 0.14$ to $0.51 ; \mathrm{P}<0.0001)$ in the TAVI group were superior to those in the SAVR group. The differences in all-cause mortality, cardiovascular mortality, stroke, TIA, MI, and PPI between the TAVI and SAVR groups were not statistically significant.

\section{Discussion}

Since currently established guidelines do not recommend the use of TAVI in low-risk surgical patients AS, our study aimed to evaluate the efficacy and effectiveness of TAVI in this patient subset by comparing 
the clinical outcomes of TAVI and SAVR at 30-day, 1-year, and 2-year follow-up time frames. This study included 3 RCTs, comprising 2633 patients, and used a meta-analysis to compare the aforementioned outcomes. Kolte et al. reported that TAVI was associated with a lower risk of cardiovascular and all-cause mortality at 1 year. ${ }^{[21]}$. Our 1-year follow-up had similar results; however, their study did not report outcomes at other follow-up time intervals. In reviewing the 2-year results of the newly released PARTNER III trial, we found that the low-risk patients who underwent TAVI at the 30-day and 1-year follow-up outperformed those who underwent SAVR in cardiovascular mortality, acute kidney injury (stage 2 or 3), NAF, and life-threatening or significant bleeding. However, TAVI resulted in a higher risk of PPI during the same time period. Compared with SAVR at the 2-year follow-up, there was no significant difference in cardiovascular and all-cause mortality for patients who underwent TAVI. Therefore, TAVI can reduce mortality and complications at the 30-day and 1-year follow-up, but at the 2-year follow-up, most of the results demonstrated no significant difference. Most notably, the 5-year follow-up of the PARTNER trial noted patients who underwent TAVI with a higher risk of death or disabling strokes. ${ }^{[22,23]}$ Furthermore, Barili et al. performed time-interval modelling, incorporating 3 RCTs (including the PARTNER trial), and found that TAVI was associated with better survival in the first few months after implantation and was a risk factor for all-cause mortality after 40 months. ${ }^{[24]}$ Although these trials were conducted with patients at intermediate and high risk, the results still have important significance to our research conclusions. It reminds us that over time, the risk of mortality and complications after TAVI may increase rapidly, which corresponds to our discovery in the 2-year clinical results.

The PARTNER III trial using the SAPIEN 3 valve has achieved superior results. According to the analysis of Deharo, the design of SAPIEN 3 is easier to fit the Landing Zone, which reduces the risk of cardiovascular complications after TAVI. ${ }^{[25,26]}$ This may also be the reason for the large heterogeneity of TIA and PPI in our finding. Different valves used in various experiments affect the heterogeneity of the analysis. Although the new generation of the valve reduces the incidence of PPI, compared to SAVR, the incidence of PPI after TAVI is still higher. Recent studies have shown that PPI is associated with late all-cause mortality and increased risk of hospitalisation due to cardiac failure ${ }^{[27]}$ Therefore, reducing the incidence of PPI after TAVI is an important issue to be considered and an interesting area for valve improvement.

Valve degeneration is another TAVI-associated complication that should be considered. Once it occurs, valve-in-valve implantation is indicated ${ }^{[28,29]}$, and it is a complex operative procedure. Postoperatively, device malposition and ostial coronary obstruction are also common TAVI-associated complications. Only the NOTION trial reports data on valve conditions in low-risk surgical patients with AS undergoing TAVI for more than 5 years ${ }^{[30]}$; therefore, there is insufficient data to analyse this problem. Moreover, most of the patients undergoing TAVI in the current RCTs are over 75 years old; therefore, their life expectancy is much less than the expected valve use time, hindering the valve durability study. RCTs need to be conducted among relatively younger patients to assess long-term follow-up, providing more effective data for future meta-analyses. 
Finally, based on the optimal performance of TAVI at the 30-day and the 1-year clinical follow-up and the continuous replacement of the operative valve, TAVI appears to be a very promising procedure in low-risk surgical patients with AS. The eventual use of TAVI in older patients with a shortened life expectancy is reasonable. However, we should also note the changes at the 2-year TAVI follow-up and the potential clinical complications of PPI and valve degeneration. In lieu of these results, the decision to use TAVI in patients with a longer life expectancy has yet to be recommended.

There were several limitations of this study. First, study omissions occurred due to their absence from the search database, resulting in eventual publication bias. Second, some inevitable differences in baseline characteristics between studies affect the accuracy of the results. Third, there is significant variability in the literature of the definitions for valve type, surgical risk, and outcomes, leading to possible discrepancies in the results.

\section{Conclusions}

In low-risk surgical patients with AS, the clinical efficacy of TAVI was superior to that of SAVR at the 30day and 1-year follow-up. At the 2-year follow-up, with the exception of the decreased NAF risk, there was no significant difference in all-cause mortality, cardiovascular mortality, and life-threatening or significant bleeding. However, potential late TAVI-associated complications, such as valvular degeneration and PPI are important clinical concerns that must be considered when weighing treatment options for AS.

\section{Abbreviations}

AS Aortic stenosis

TAVI Transcatheter aortic valve implantation

SAVR Surgical aortic valve replacement

RCTs Randomised controlled trials

STS PROM Society of Thoracic Surgeons Predicted Risk of Mortality

TIA Transient ischaemic attack

MI Myocardial infarction

PPI Permanent pacemaker implantation

NAF New atrial fibrillation

GRADE Grading of Recommendations, Assessment, Development and Evaluation

RR Relative risk 
I $^{2}$ |-square

\section{Declarations}

\section{Ethics approval and consent to participate}

Not applicable.

\section{Consent for publication}

Not applicable.

\section{Availability of data and materials}

All data generated or analyzed during this study are included in this published article and its supplementary information files.

\section{Competing interests}

The authors have nothing to disclose.

\section{Funding}

This work was funded by the National Natural Science Foundation of China (U2005202), the Fujian Province Major Science and Technology Program (2018YZ001-1), the Natural Science Foundation of Fujian Province (2020J02056), and Fujian Provincial Health Technology Project(2019-ZQN-50).

\section{Author contributions}

CGC and BBX collected and analyzed the data and wrote the manuscript; QFD designed the study; XYZ and WCL collected the data; LWC and ZHQ verified the validity of the article and revised the manuscript. All authors read and approved the final manuscript.

\section{Acknowledgements}

Not applicable.

\section{References}

1. Carabello BA, Paulus WJ. Aortic stenosis. Lancet. 2009;373:956-66.

2. Holmes DR, Mack MJ, Kaul S, Agnihotri A, Alexander KP, Bailey SR, et al. 2012 ACCF/AATS/SCAI/STS expert consensus document on transcatheter aortic valve replacement. J Am Coll Cardiol. 2012;59:1200-54. 
3. Cribier A, Eltchaninoff H, Bash A, Borenstein N, Tron C, Bauer F, et al. Percutaneous transcatheter implantation of an aortic valve prosthesis for calcific aortic stenosis: first human case description. Circulation. 2002;106:3006-08.

4. Mack MJ, Leon MB, Smith CR, Miller DC, Moses JW, Tuzcu EM, et al. 5-year outcomes of transcatheter aortic valve replacement or surgical aortic valve replacement for high surgical risk patients with aortic stenosis (PARTNER 1): a randomised controlled trial. Lancet. 2015;385:2477-84.

5. Leon MB, Smith CR, Mack MJ, Makkar RR, Svensson LG, Kodali SK, et al. Transcatheter or Surgical Aortic-Valve Replacement in Intermediate-Risk Patients. N Engl J Med. 2016;374:1609-20.

6. Nishimura RA, Otto CM, Bonow RO, Carabello BA, Erwin JP, Fleisher LA, et al. 2017 AHA/ACC Focused Update of the 2014 AHA/ACC Guideline for the Management of Patients With Valvular Heart Disease: A Report of the American College of Cardiology/American Heart Association Task Force on Clinical Practice Guidelines. Circulation. 2017;135:e1159-e95.

7. Faroux L, Chen S, Muntané-Carol G, Regueiro A, Philippon F, Sondergaard L, et al. Clinical impact of conduction disturbances in transcatheter aortic valve replacement recipients: a systematic review and meta-analysis. Eur Heart J. 2020;41:2771-81.

8. Popma JJ, Michael Deeb G, Yakubov SJ, Mumtaz M, Gada H, O'Hair D, et al. Transcatheter aorticvalve replacement with a self-expanding valve in low-risk patients. N Engl J Med. 2019;380:1706-15.

9. Thyregod HG, Steinbrüchel DA, Ihlemann N, Nissen H, Kjeldsen BJ, Petursson P, et al. Transcatheter Versus Surgical Aortic Valve Replacement in Patients With Severe Aortic Valve Stenosis: 1-Year Results From the All-Comers NOTION Randomized Clinical Trial. J Am Coll Cardiol. 2015;65:218494.

10. Otto CM, Nishimura RA, Bonow RO, Carabello BA, Erwin JP 3rd, Gentile F, et al. 2020 ACC/AHA Guideline for the Management of Patients With Valvular Heart Disease: A Report of the American College of Cardiology/American Heart Association Joint Committee on Clinical Practice Guidelines. Circulation. 2021;143:e72-227.

11. Leon MB, Mack MJ, Hahn RT, Thourani VH, Makkar R, Kodali SK, et al. Outcomes 2 Years After Transcatheter Aortic Valve Replacement in Patients at Low Surgical Risk. J Am Coll Cardiol. 2021;77:1149-61.

12. Shamseer L, Moher D, Clarke M, Ghersi D, Liberati A, Petticrew M, et al. Preferred reporting items for systematic review and meta-analysis protocols (PRISMA-P) 2015: elaboration and explanation. BMJ. 2015;350:g7647.

13. Liberati A, Altman DG, Tetzlaff J, Mulrow C, Gøtzsche PC, loannidis JPA, et al. The PRISMA statement for reporting systematic reviews and meta-analyses of studies that evaluate health care interventions: explanation and elaboration. Ann Intern Med. 2009;151:W65-94.

14. Søndergaard L, Steinbrüchel DA, Ihlemann N, Nissen H, Kjeldsen BJ, Petursson P, et al. Two-Year Outcomes in Patients With Severe Aortic Valve Stenosis Randomized to Transcatheter Versus Surgical Aortic Valve Replacement: The All-Comers Nordic Aortic Valve Intervention Randomized Clinical Trial. Circ Cardiovasc Interv. 2016;9(6):e003665. 
15. Guyatt GH, Oxman AD, Vist GE, Kunz R, Falck-Ytter Y, Alonso-Coello P, et al. GRADE: an emerging consensus on rating quality of evidence and strength of recommendations. BMJ. 2008;336:924-6.

16. Ades AE, Lu G, Higgins JPT. The interpretation of random-effects meta-analysis in decision models. Med Decis Making. 2005;25:646-54.

17. Ioannidis JPA, Patsopoulos NA, Evangelou E. Uncertainty in heterogeneity estimates in metaanalyses. BMJ. 2007;335:914-16.

18. Higgins JPT, Thompson SG, Deeks JJ, Altman DG. Measuring inconsistency in meta-analyses. BMJ. 2003;327:557-60.

19. Egger M, Davey Smith G, Schneider M, Minder C. Bias in meta-analysis detected by a simple, graphical test. BMJ. 1997;315:629-34.

20. Begg CB, Mazumdar M. Operating characteristics of a rank correlation test for publication bias. Biometrics. 1994;50:1088-101.

21. Kolte D, Vlahakes GJ, Palacios IF, Sakhuja R, Passeri JJ, Inglessis I, et al. Transcatheter Versus Surgical Aortic Valve Replacement in Low-Risk Patients. J Am Coll Cardiol. 2019;74:1532-40.

22. Makkar RR, Thourani VH, Mack MJ, Kodali SK, Kapadia S, Webb JG, et al. Five-Year Outcomes of Transcatheter or Surgical Aortic-Valve Replacement. N Engl J Med. 2020;382:799-809.

23. Van Belle E. TAVR at 5 Years - Rematch or Swan Song for Surgery? N Engl J Med. 2020;382:86768.

24. Barili F, Freemantle N, Pilozzi Casado A, Rinaldi M, Folliguet T, Musumeci F, et al. Mortality in trials on transcatheter aortic valve implantation versus surgical aortic valve replacement: a pooled metaanalysis of Kaplan-Meier-derived individual patient data. Eur J Cardiothorac Surg. 2020;58:221-29.

25. Deharo P, Bisson A, Herbert J, Lacour T, Saint Etienne C, Grammatico-Guillon L, et al. Impact of Sapien 3 Balloon-Expandable Versus Evolut R Self-Expandable Transcatheter Aortic Valve Implantation in Patients With Aortic Stenosis: Data From a Nationwide Analysis. Circulation. 2020;141:260-8.

26. Schymik G, Schröfel H, Heimeshoff M, Luik A, Thoenes M, Mandinov L. How to adapt the implantation technique for the new SAPIEN 3 transcatheter heart valve design. J Interv Cardiol. 2015;28:82-9.

27. Jørgensen TH, De Backer O, Gerds TA, Bieliauskas G, Svendsen JH, Søndergaard L. Mortality and Heart Failure Hospitalization in Patients With Conduction Abnormalities After Transcatheter Aortic Valve Replacement. JACC Cardiovasc Interv. 2019;12:52-61.

28. Danny D, John W, Stephen B, Sabine B, David H-S, Antonio C, et al. Transcatheter Aortic Valve Replacement for Degenerative Bioprosthetic Surgical Valves. Circulation. 2012;126:2335-44.

29. Bidar E, Folliguet T, Kluin J, Muneretto C, Parolari A, Barili F, et al. Postimplant biological aortic prosthesis degeneration: challenges in transcatheter valve implants. Eur J Cardiothorac Surg. 2019;55:191-200. 
30. Thyregod HGH, Ihlemann N, Jørgensen TH, Nissen H, Kjeldsen BJ, Petursson P, et al. Five-Year Clinical and Echocardiographic Outcomes from the Nordic Aortic Valve Intervention (NOTION) Randomized Clinical Trial in Lower Surgical Risk Patients. Circulation. 2019;139:2714-23.

\section{Figures}
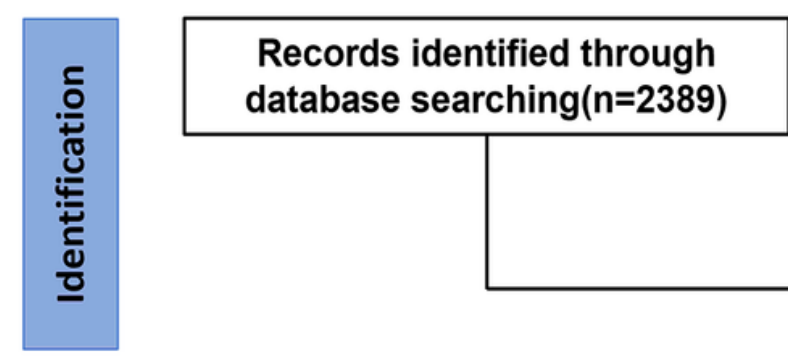

Additional records identified

database searching $(n=2389)$ through other sources( $n=0)$
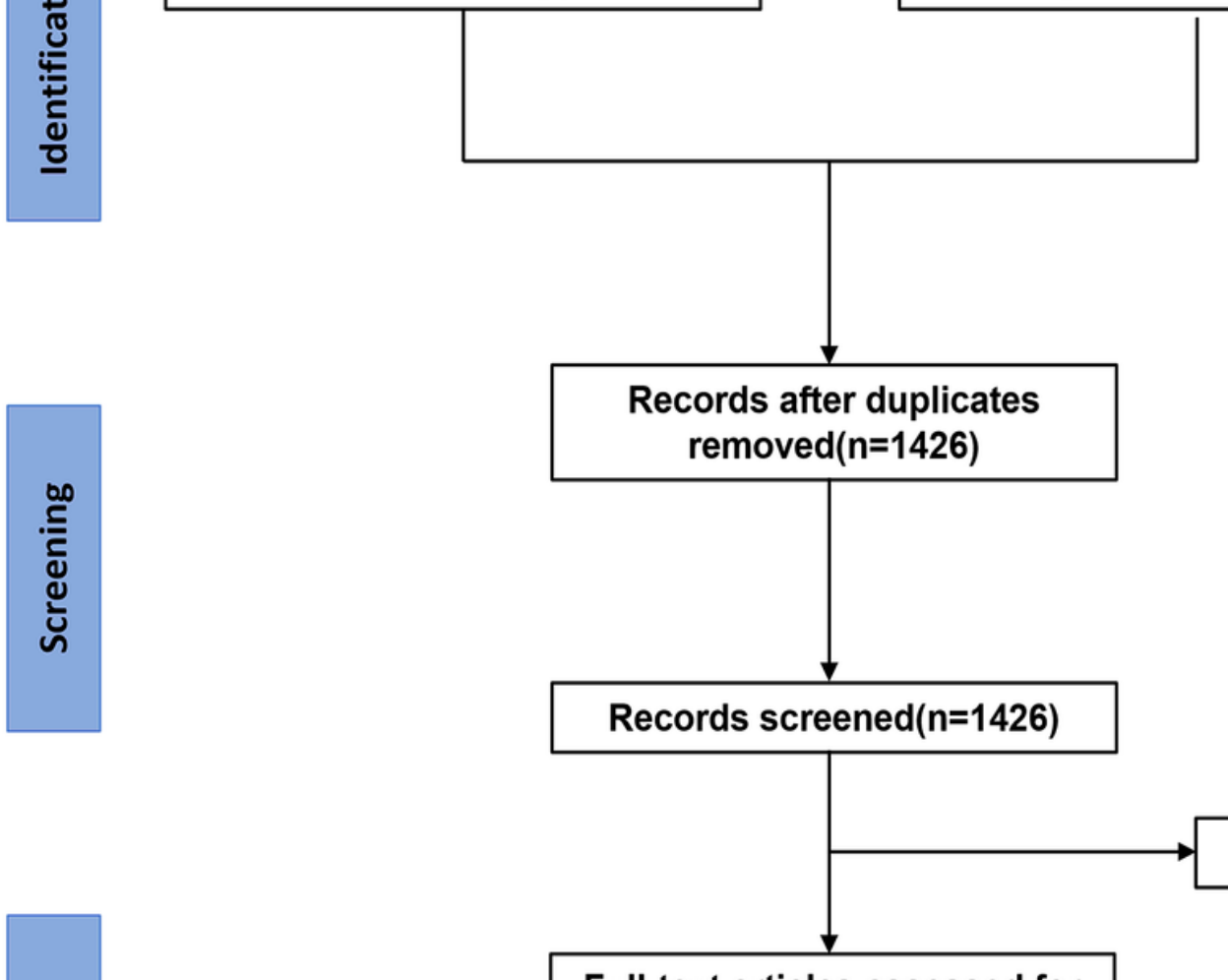

Records excluded(n=1394)
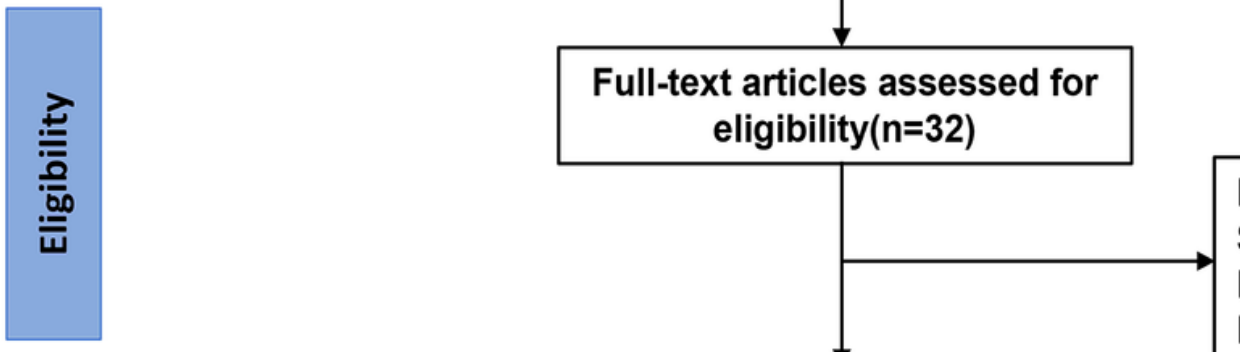

Full-text articles excluded(n=29): STS PROM $>4 \%(n=17)$

Duplicates( $n=3)$

Not RCT(n=9)

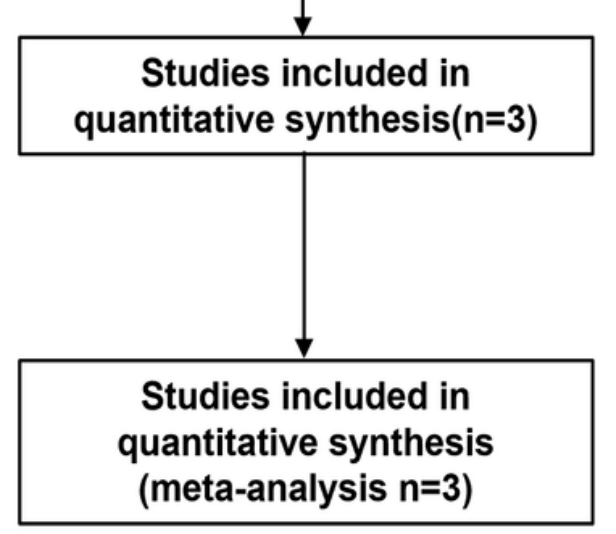

Figure 1 
Flowchart for screening and study selection process

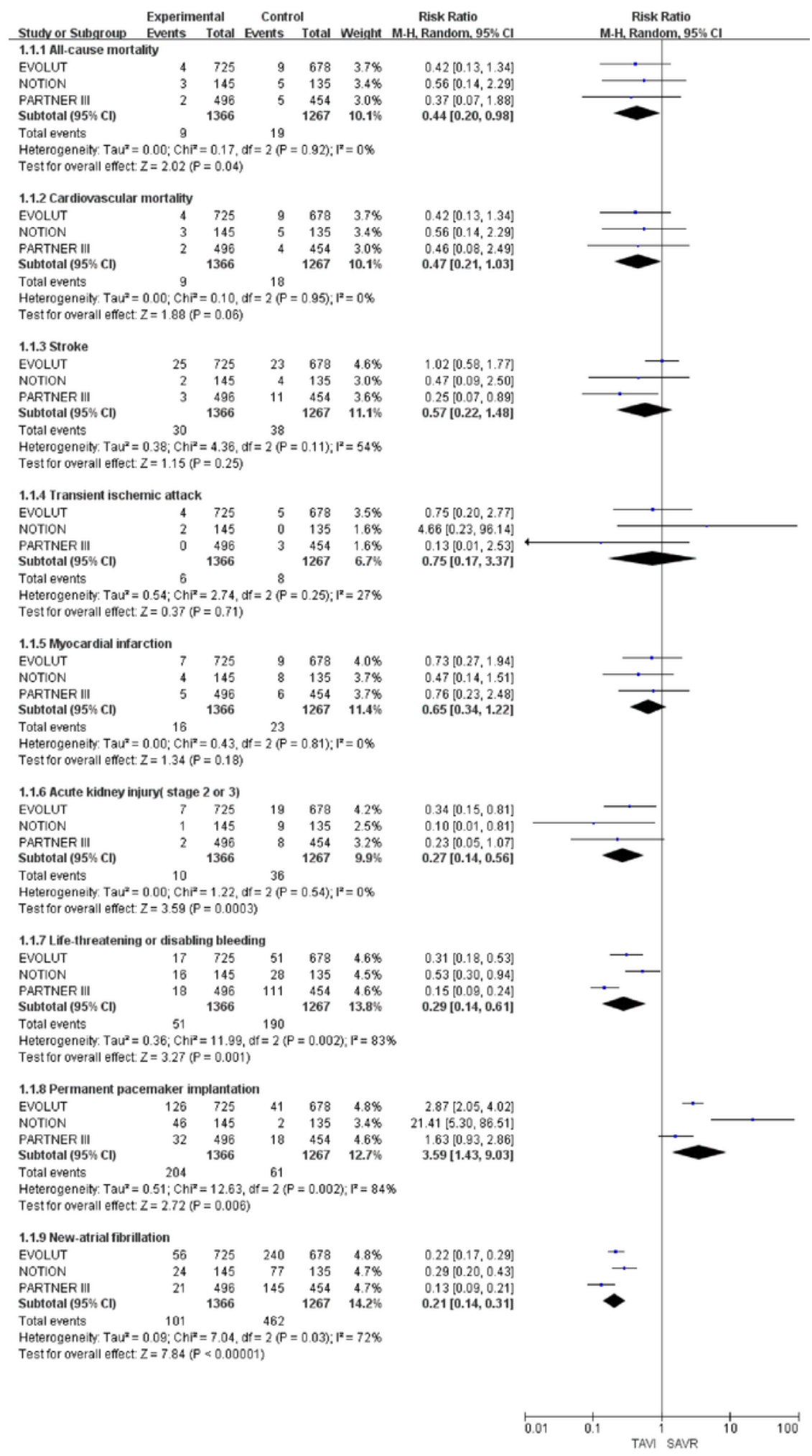

Figure 2

Forest plot for incidence of all-cause mortality, cardiovascular mortality, stroke, transient ischemic attack, myocardial infarction, acute kidney injury, life-threatening or disabling bleeding, permanent pacemaker implantation, new-atrial fibrillation at the 30-day follow-up. 


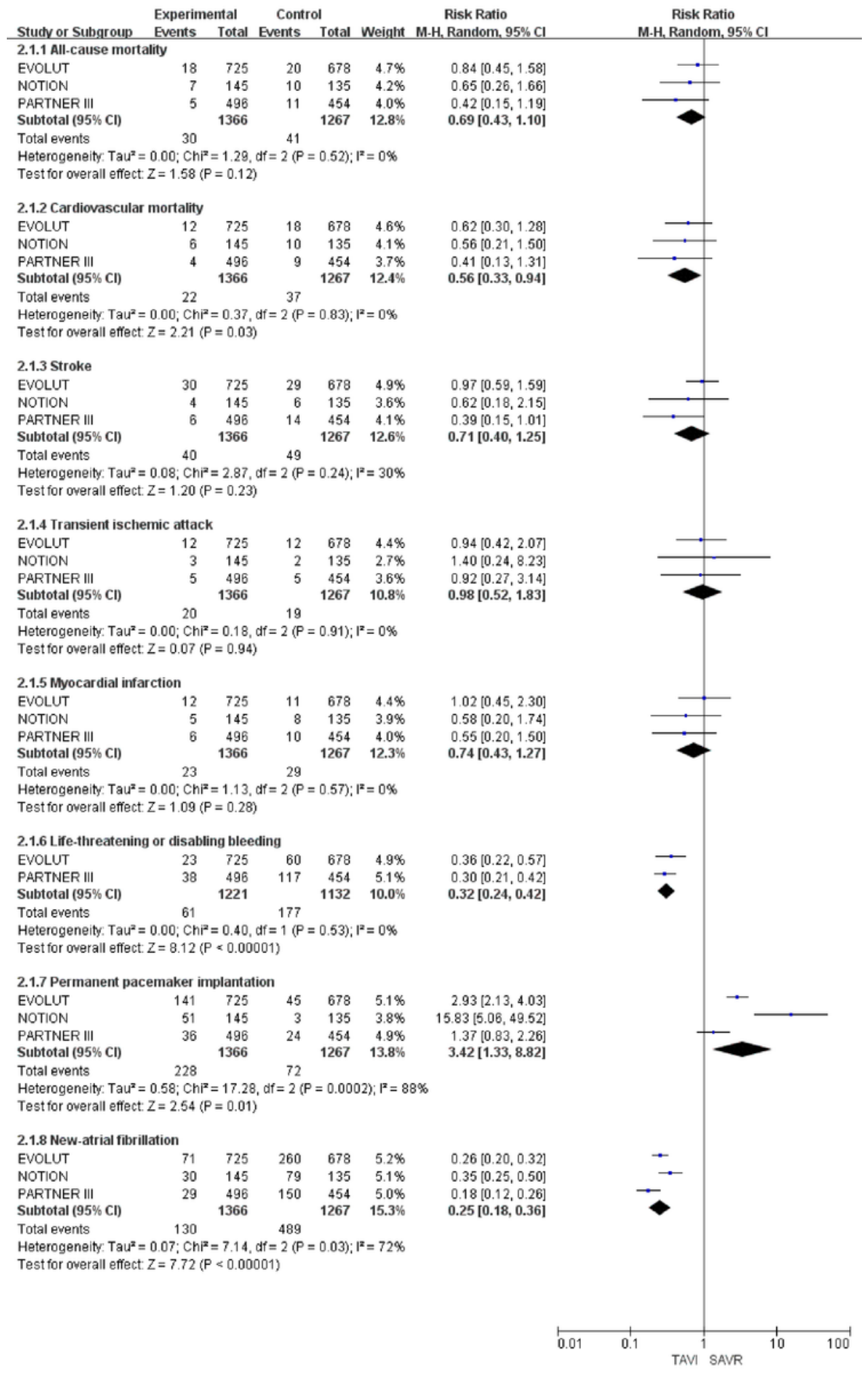

\section{Figure 3}

Forest plot for incidence of all-cause mortality, cardiovascular mortality, stroke, transient ischemic attack, myocardial infarction, acute kidney injury, life-threatening or disabling bleeding, permanent pacemaker implantation, new-atrial fibrillation at the 1-year follow-up. 
TAVI

SAVR

Risk Ratio

Risk Ratio

Study or Subgroup Events Total Events Total Weight M-H, Random, 95\% Cl 3.1.1 All-cause mortality

PARTNER III

$11 \quad 145$

$13 \quad 135 \quad 7.3 \%$

496

$14 \quad 454 \quad 7.3 \%$

$58914.6 \%$

Total events

23

27

Heterogeneity: Tau $^{2}=0.00 ; \mathrm{Chi}^{2}=0.00, \mathrm{df}=1(\mathrm{P}=0.99) ; \mathrm{I}^{2}=0 \%$

Test for overall effect: $Z=0.87(P=0.38)$

3.1.2 Cardiovascular mortality

$\begin{array}{lrrrrrr}\text { NOTION } & 9 & 145 & 12 & 135 & 7.1 \% & 0.70[0.30,1.60] \\ \text { PARTNER III } & 8 & 496 & 12 & 454 & 6.9 \% & 0.61[0.25,1.48] \\ \text { Subtotal (95\% CI) } & & \mathbf{6 4 1} & & \mathbf{5 8 9} & \mathbf{1 4 . 0} \% & \mathbf{0 . 6 6}[\mathbf{0 . 3 6}, \mathbf{1 . 2 0}]\end{array}$

Total events

$17 \quad 24$

Heterogeneity: $\operatorname{Tau}^{\mathbf{2}}=0.00 ; \mathrm{Ch}^{\mathbf{2}}=0.05, \mathrm{df}=1(\mathrm{P}=0.83) ; \mathrm{I}^{\mathbf{2}}=0 \%$

Test for overall effect: $Z=1.37(P=0.17)$

\begin{abstract}
3.1.3 Stroke
NOTION

PARTNER III

Subtotal $(95 \% \mathrm{Cl})$

Total events

Heterogeneity: Tau $^{2}=0.00 ; \mathrm{Chi}^{2}=0.00, \mathrm{df}=1(\mathrm{P}=0.96) ; \mathrm{I}^{2}=0 \%$

Test for overall effect: $Z=1.23(P=0.22)$
\end{abstract}

3.1.4 Transient ischemic attack

$\begin{array}{lrrrrrr}\text { NOTION } & 8 & 145 & 4 & 135 & 6.0 \% & 1.86[0.57,6.04] \\ \text { PARTNER III } & 5 & 496 & 7 & 454 & 6.1 \% & 0.65[0.21,2.05] \\ \text { Subtotal }(95 \% \mathrm{Cl}) & & \mathbf{6 4 1} & & \mathbf{5 8 9} & \mathbf{1 2 . 0 \%} & \mathbf{1 . 0 9 [ 0 . 3 9 , 3 . 0 4 ]} \\ \text { Total events } & 13 & & 11 & & & \end{array}$

Heterogeneity: Ta $^{2}=0.20 ; \mathrm{Chi}^{2}=1.57, \mathrm{df}=1(\mathrm{P}=0.21) ; \mathrm{I}^{2}=36 \%$

Test for overall effect: $Z=0.17(P=0.87)$

3.1.5 Myocardial infarction

$\begin{array}{lrrrrr}\text { NOTION } & 7 & 145 & 8 & 135 & 6.6 \% \\ \text { PARTNER III } & 12 & 496 & 14 & 454 & 7.3 \% \\ \text { Subtotal }(\mathbf{9 5} \% \mathrm{Cl}) & & \mathbf{6 4 1} & & \mathbf{5 8 9} & \mathbf{1 3 . 9} \% \\ \text { Total events } & 19 & & 22 & & \end{array}$

Heterogeneity: Tau $^{2}=0.00 ; \mathrm{Chi}^{2}=0.00, \mathrm{df}=1(\mathrm{P}=0.95) ; \mathrm{I}^{2}=0 \%$

Test for overall effect: $Z=0.74(P=0.46)$

3.1.6 Permanent pacemaker implantation

$\begin{array}{lrrrrrr}\text { NOTION } & 55 & 145 & 5 & 135 & 6.9 \% & 10.24[4.23,24.81] \\ \text { PARTNER III } & 44 & 496 & 30 & 454 & 8.2 \% & 1.34[0.86,2.10] \\ \text { Subtotal (95\% CI) } & & \mathbf{6 4 1} & & \mathbf{5 8 9} & \mathbf{1 5 . 1} \% & \mathbf{3 . 5 8}[\mathbf{0 . 4 5}, \mathbf{2 8 . 7 4 ]} \\ \text { Total events } & 99 & & 35 & & & \end{array}$

$\begin{array}{lcl}\text { Total events } & 99 & 35 \\ \text { Heterogeneity: } \text { Tau }^{2}=2.13 ; \mathrm{Chi}^{2}=17.67, \mathrm{df}=1(\mathrm{P}<0.0001) ;\left.\right|^{2}=94 \%\end{array}$

Test for overall effect: $Z=1.20(P=0.23)$

3.1.7 New-atrial fibrillation

$\begin{array}{lrrrrrr}\text { NOTION } & 32 & 145 & 80 & 135 & 8.4 \% & 0.37[0.27,0.52] \\ \text { PARTNER III } & 33 & 496 & 153 & 454 & 8.4 \% & 0.20[0.14,0.28] \\ \text { Subtotal (95\% Cl) } & & \mathbf{6 4 1} & & \mathbf{5 8 9} & \mathbf{1 6 . 8} \% & \mathbf{0 . 2 7}[\mathbf{0 . 1 4}, \mathbf{0 . 5 1}] \\ \text { Total events } & 65 & & 233 & & & \end{array}$

Heterogeneity: $\operatorname{Tau}^{\mathbf{2}}=0.18 ; \mathrm{Chi}^{\mathbf{2}}=6.80, \mathrm{df}=1(\mathrm{P}=0.009) ; \mathrm{I}^{\mathrm{z}}=85 \%$

Test for overall effect: $Z=4.01(P<0.0001)$
$.79[0.37,1.70]$

$0.78[0.37,1.68]$

$0.67[0.22,2.05]$

$0.69[0.33,1.44]$

$0.68[0.37,1.26]$

$0.81[0.30,2.19]$

$0.78[0.37,1.68]$

$0.80[0.44,1.45]$ 
This is a list of supplementary files associated with this preprint. Click to download.

- PRISMA2020checklist.docx

- Supplement.docx 